\title{
Does demonetization affect innovation? A study of cash heavy businesses in India: A Fantasy Pitch
}

\author{
Robin Carrick and William Tunny ${ }^{\mathrm{a}, 1}$ \\ ${ }^{\text {a }}$ The University of Queensland, Australia
}

\begin{abstract}
A bstract: This paper outlines the use of Faff's $(2015,2017)$ pitching research template to create a research pitch for a "fantasy" topic. The process of using each section in the template and the scholars' views on the process is detailed and is followed by noting the key learning outcome of the exercise; having the freedom to choose a "fantasy" topic and working through the template from scratch led to the scholars gaining a deeper understanding of how to use the pitching research templatefor starting research.
\end{abstract}

K eywords: Pitching research, template, reverse engineering, fantasy pitch, innovation, demonetisation

\section{J EL codes: A23; O30}

\section{Introduction}

The purpose of this letter is to outline how we, as aspiring research students, were able to better acquaint ourselves with planning research using Faff's $(2015,2017)$ pitching research template through a "fantasy pitching" exercise. This exercise is novel in the sense that its stark contrast to more methodological pitching template

\footnotetext{
${ }^{1}$ Corresponding authors: University of Queensland Business School; 39 Blair Dr, St Lucia QLD 4067; tel. (+61) 73346 8100; email addresses: robin.carrick@uqconnect.edu.au, william@tunny.comau
} 
tasks allows for the development of more abstract reasoning and learning for the process as a whole. While seemingly simple at face value, this task provides a unique pedagogic opportunity for overcoming challenges encountered by early career researchers.

This task was set by Professor Faff for the 2016/2017 Summer Research Scholars at the University of Queensland, who had significant exposure to the template and was completed in pairs. Our team, represents one of those pairs. Robin is entering his third year at the University of Queensland studying Mathematics and Commerce. Participation in the summer research program piqued his interest in pursuing an Honours degree. His academic interests lie in data analysis and macroeconomic policy. William had just recently graduated with a Bachelor of Commerce, majoring in finance, from the University of Queensland. In 2017 he will commence his Honours, in the UQ Business School, and he is interested in researching the fiedd of behavioural finance.

The Fantasy Pitching exercise enabled students to further develop their pitching research proficiency in a low stress, constructive environment. Moreover, complementing the written component, students had the opportunity to orally present the topic. While mostly involving self-di rected peer learning, we benefited from helpful feedback from Professor Faff and also from as fellow summer research scholars through informal discussions.

The remainder of this pitching research letter is organised as follows. Section 2 provides a brief commentary on the completed fantasy pitch. Section 3 covers personal reflections from both members of the team Lastly, this paper concludes in Section 4.

\section{Brief Commentary on the Fantasy Pitching E xercise}

\subsection{Background information}

The fantasy pitching exercise combined the theme of "Dirty Money" (relating to the current Indian economic policy of demonetisation) with the research question from a previous exercise; the pitching "spar" (see, Faff et al., 2017). The pitch "sparring" activity was a "lead-in" joint effort between the two named authors of this PRL, with the aim of reverse engineering a research paper of choice into the "Pitching Research" template (Faff, 2015, 2017). The research paper that we chose was "Does going public affect innovation?" by (Bernstein, 2015). From this exercise, the research question was "what are the effects of going public on firm innovation and what are the key differences between firms that went public and those that withdrew their IPO filing?" Our task was to create a research topic that integrated the aforementioned topic with the theme of dirty money. 
A key aspect of the exercise was the great freedom of choice for the research topic; which could be very challenging to test, however it could still be used in the pitch, due to its totally fictional nature. The purpose of the exercise was to develop a greater understanding of how the pitching template could most effectively be used.

To start the process, we read various newspaper articles on the economic situation in India to position our minds toward focusing on the issue. In our first meeting, we had to create a brief draft for the working tite, basic research question, key papers and motivation. Once the basic outline was completed, the template was ready to be utilised.

\subsection{The reverse engineering process}

Our completed Fantasy Pitch is shown in Table 1.

\section{W orking Title}

The title chosen was "Does demonetization affect innovation? A study of cash heavy businesses in India". We agreed that this title accurately summarised our a im for the paper in a succinct and informative manner.

\section{Basic Research Question}

The key feature of our paper is the link between innovation and demonetization. Drawing a link required a fair amount of thought and deliberation and as such was the first hurdle we faced in this exercise. We decided to focus just on the innovative activities of firms exposed to high cash turnover; a reasonable connection between the two sal ient task requirements.

\section{K ey papers}

The fantasy element of the exercise led to a slight deviation from Prof Faff's normal template content when it comes to the key papers section. In normal circumstances, the key papers ideally should be published by "gurus" in the particular field of interest and recently published in tier 1 journals. However, for the purposes of this fantasy pitch, the criteria are relaxed. There were 3 key papers chosen, one of which being a "fantasy" [fake] paper (Wane, 2015), used for the means of completing the pitch.

Moreover, we referred to an article from the Financial Review called "Narendra Modi's demonetisation hits gold and diamond merchants". The article gives a brief summary of how demonetisation is currently hitting gold and diamond merchants in India. Even though the article mainly focusses on gold and diamond merchants, a general conclusion was explicitly contained in it The conclusion that hel ped us to 
formulate our research question was that small cash-based businesses are being affected by the recent economic policy.

\section{M otivation/Puzzle}

Further research into the consequences of India's demonetization policy uncovered some significant consequences for their economy, namely $85 \%$ of their total money in circulation being affected. A short term dip in daily consumption immediately occurred; acknowledging these initial results allowed us to refocus and clearly define the scope in which we would hypothetically study. It was agreed this would be a significant undertaking and that our study would provide a model for which further studies analysing longer term results could build upon. Therefore, the subsequent effects on firm innovation, employing similar indicators used by (Bernstein, 2015), would be eval uated by including data from firms who by nature deal heavily with physical cash. A firm specific example we came up with was diamond companies due to the fact that as much as $90 \%$ of the world's rough diamonds pass through I ndia to be cut, polished or traded.

Idea

The idea that drove the intel lectual content was how we could apply the approach taken in (Bemstein, 2015) to analyse the effect that demonetisation has on firm innovation in India and compare this figure between cash heavy and non-cash heavy firms. The idea was to compare the innovation activity measured by patent citations of low physical cash heavy firms with physical cash heavy firms 3 years after demonetisation had taken effect.

\section{Data}

The data section of the template outlines the data sources that would be used to create an econometric model. For this fantasy exercise the data section did not go into detail about sample sizes, cross-sectional ity and so forth.

\section{Tools}

We decided to not focus too heavily on the quantitative aspects of our research topic as to not stray away from the true purpose of this exercise. Therefore, Bernstein's model using multivariate analysis to compare firm innovation performance was used. It was imperative, however, to specifically mention the key assumption in our model in that the effects of corruption on firm innovation is not significant (Paunov, 2016). 


\section{What's New?}

A nal ogous to the aforementioned fake key paper (Wane, 2015), we found that this type of research had not been conducted in any economy worldwide. Such is the fantasy nature of this task the "What's New?" component was relatively straightforward due to the novelty of our chosen topic. See Figure 1 for the "Mickey Mouse" diagram that best characterises the novel ty of the pitch.

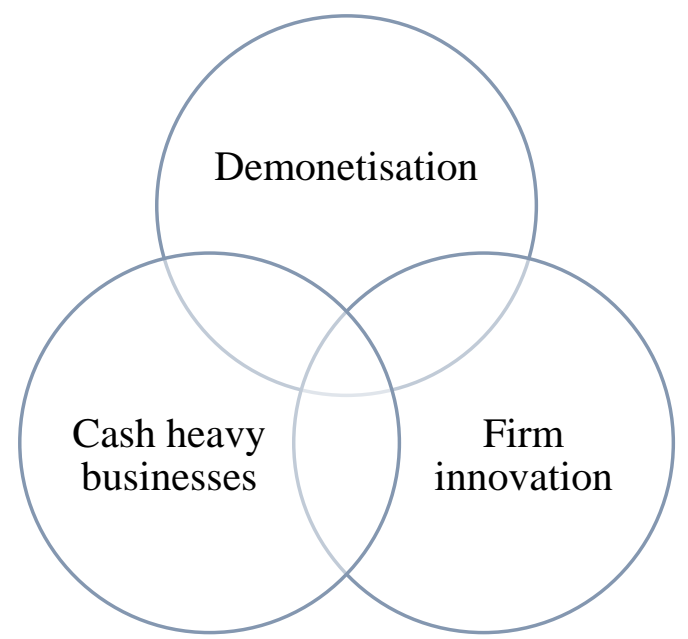

Figure 1. M ickey M ouse diagram characterizing novelty of research idea

\section{So What?}

This section outlined the significance of the research, why it is important to know the answer and out ined how maj or decisions/behaviour could be influenced by the outcome of the research. We stressed how important the research was, as India is becoming a significant player in the global economy therefore any potentially significant impact on this economy should be known and addressed.

\section{Contribution}

The contribution part outlined what the academic research would contribute to the existing literature in the field. The researchers detailed how the academic paper would produce an econometric model that would analyse one unintended consequence of the macro-economic policy pursued by the Indian government Moreover, it was stressed that the paper could potentially pave the way for a new line of policy analysis in the future. 


\section{Other C onsiderations}

Our original target journal was the Indian J ournal of Finance, however, Professor Faff encouraged us to be more ambitious and therefore we decided to target the J ournal of Finance. We recognise however, that this diametric change in targets is totally aspirational - which would not be ideal in a real setting.

\section{R eflections on learning outcomes}

A key learning outcome of the fantasy pitching process was the deeper knowledge of how to use the template that the scholars gained. Coming up with an idea from "scratch" and then going through the motions of starting the research journey is a vastly better learning method than just reading the template or even reverse engineering a research paper into its components.

One aspect that the scholars learnt was how starting research and using the pitching research template is a non-linear process, not merely a form filling exercise. For example, the "idea" section will link in with the "motivation" section and the "what's new" and "so what" parts link back to the "motivation" and "idea". The fantasy aspect helped us not be too concerned about the minutiae of the data and tools sections, thereby allowing us to learn how the whole process of starting research is an iterative process.

The oral component is imperative to the effectiveness and success of the overall pitch. This was the summer research scholars first opportunity to orally present a pitch. The template also al lowed for smooth transitions between speakers without impeding flow. As well as a printout of the completed template, visual aids were harnessed as if we were presenting at a pitching research symposium. The pitch framework assumption that the audience are experts did not negatively affect audience understanding given it was made up of Professor Faff and our fellow summer research scholars. This question was raised following our attendance of a pitching research symposium where we had to pretend we were all experts in the field when eval uating the final ists' pitches (Faff et al., 2017).

This exercise is arguably the most novel approach for practicing pitching research. Previous tasks, while effective, were quite methodologica. When juxtaposed, the pedagogic features appear to complement the student's understanding as evident through peer reflections post presentation. This method provided artificial challenges faced by early career researchers which would require abstract reasoning in order to pass through the threshold of understanding and research direction. 


\section{Conclusion}

This letter outlines how we were able to better acquaint ourselves with planning research using Faff's $(2015,2017)$ pitching research template through a "fantasy pitching" exercise Our recommendation to future scholars is to try a fantasy pitching exercise like the one we describe. This allows a refreshing freedom - to work through the template with an unorthodox research topic, step back and look at 'the big picture' of how to effectively use the template - learn how to practice pitching research in a novel and fictional context.

\section{R eferences}

Bemstein, S. (2015) "Does going public affect innovation?", The Journal of Finance, vol. 70, no. 4: 1365-1403

Faff, R., Carrick, R., Chen, A., Dallest, K., Escobar, M., Foley, G., Gill, C., Khong, B., Liu, M., McCullough, J., Ndugwa, Z., Nguyen, B., O'Brien, S., Orole, F., Qureshi, A., Rad, H., Rekker, S., Shahzad, S., Smith, M., Tunny, W., Wallin, A. (2017) "Motivating Postgrad Research Students to Pitch Their Ideas: What Have We Learned from "Pitching Research" Competitions at UQ?" SSRN: https://ssrn.com/abstract=2899942

Faff, R., Carrick, R., Chen, A., Escobar, M., Khong, B., Nguyen, B., Tunny, W., (2017) "Pitching Research: A Reverse-Engineer "Sparring" Experiment with UQ Summer Research Scholars" SSRN: https://ssm.com/abstract=2903811

Faff, R. (2017) "Pitching Research", SSRN: https://ssrn.com/abstract=2462059

Paunov, C. (2016) "Corruption's asymmetric impacts on firm innovation", J ournal of Development Economics, vol.118: 216-231 
Does demonetization affect innovation? A study of cash heavy businesses in India:

A Fantasy Pitch

Table 1: Complete Fantasy Pitch of "Does demonetisation affect innovation? A study of cash heavy businesses in India."

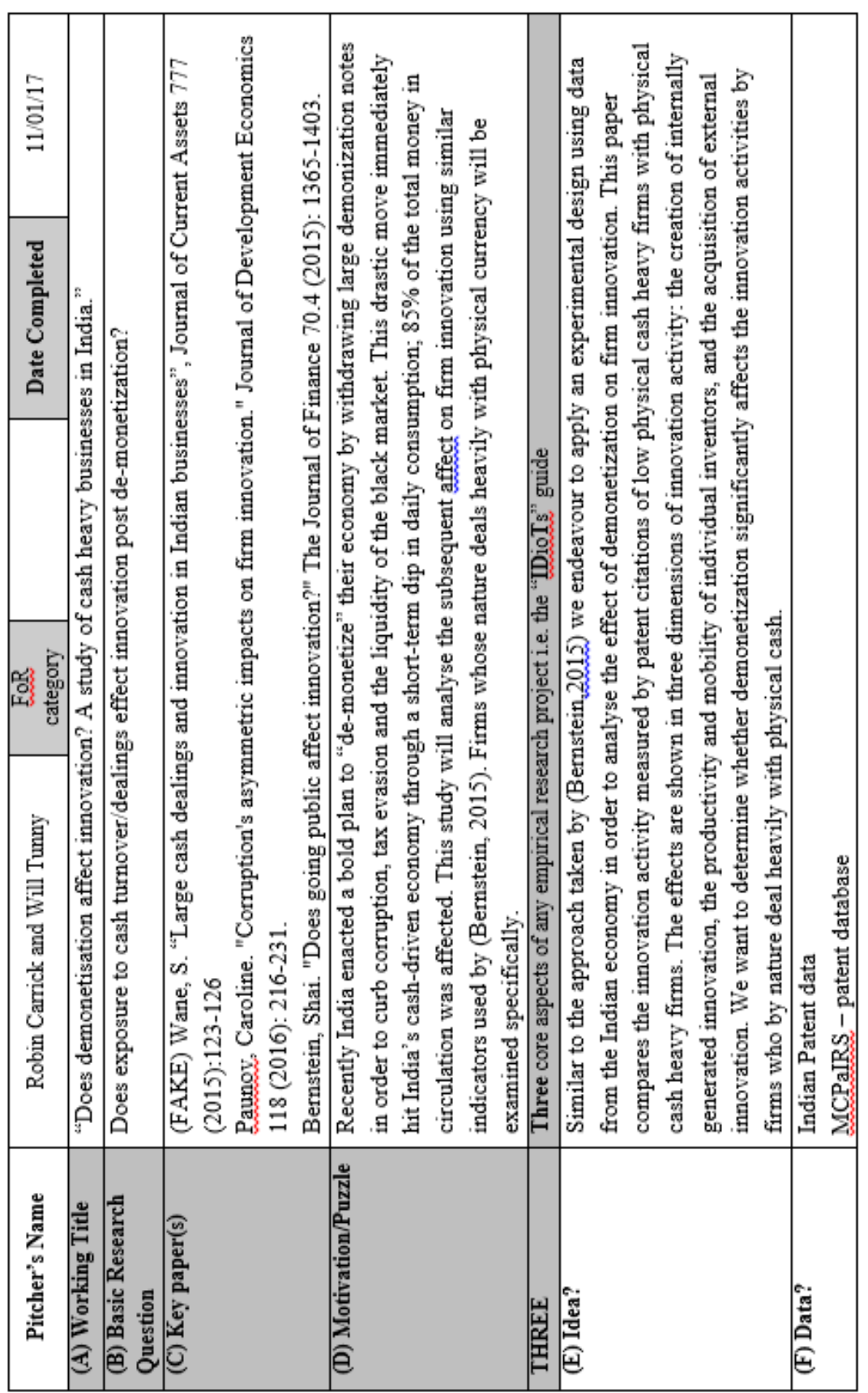

Vol. 17, No. 3 


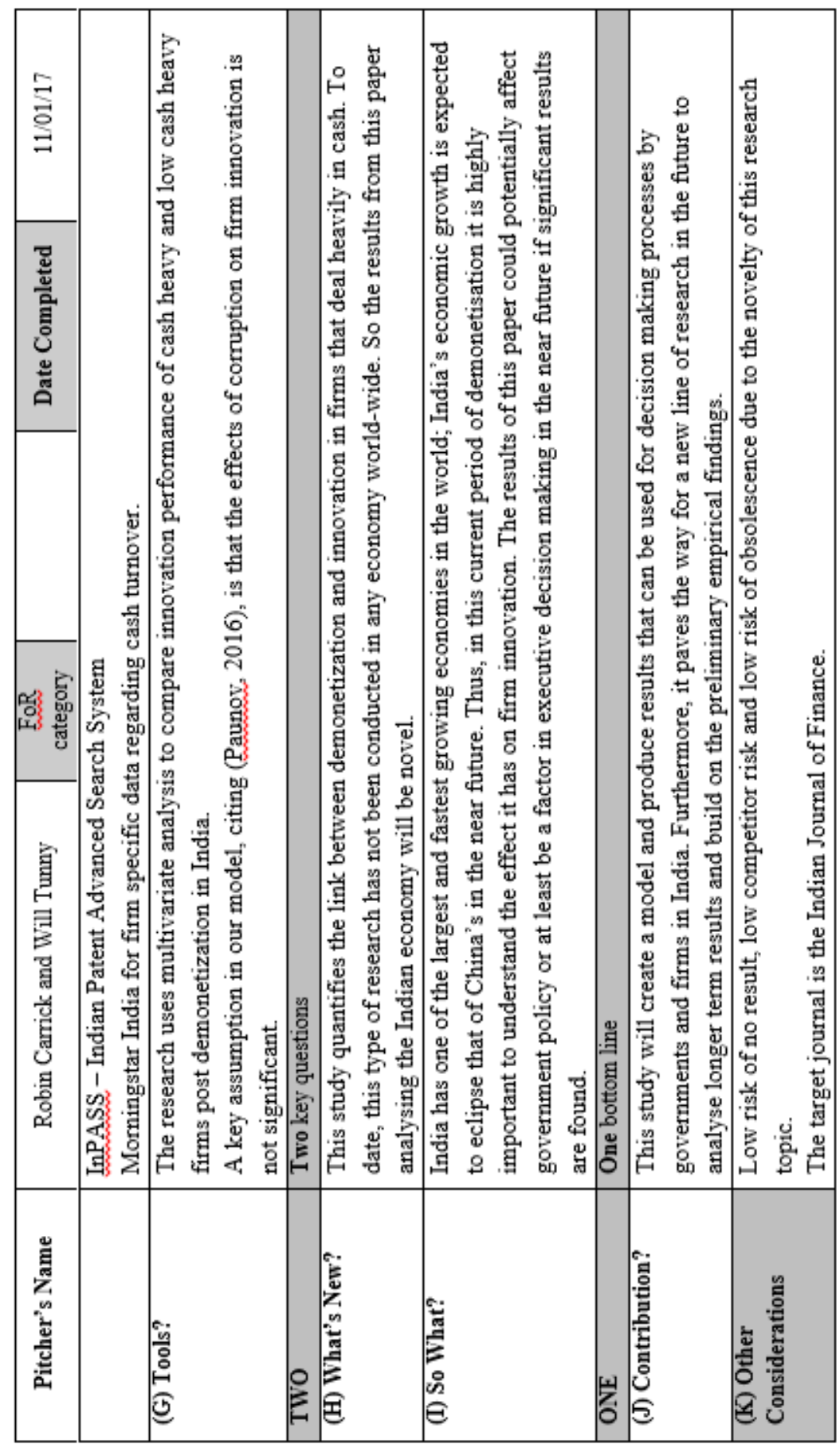

